\title{
Clinical features of the congenital vitreoretinopathies
}

AO Edwards

Keywords: vitreoretinal degeneration; inherited vitreoretinopathy; vitreous; retinal detachment; cataract; collagen

The inherited vitreoretinal degenerations or vitreoretinopathies are characterized by congenital and acquired disorders of the eye including early onset cataract, anomalies of the vitreous manifesting as optically empty vitreous, course fibrils, and membranes, and retinal detachment. These diseases include Stickler syndrome types I (STL1) and II (STL2), usually caused by mutations in COL2A1 and COL11A1 respectively. Wagner syndrome (WGN1) is associated with mutations in versican (CSPG2) and snowflake vitreoretinal degeneration (SVD) with a mutation in a potassium channel (KCNJ13). The cataract is often cortical and may be wedge-shaped, but does not distinguish between the different syndromes. The congenital vitreous defect is usually characterized as fibrillar degeneration (STL2, WGN1, and SVD) or as a vestigial membrane just behind the lens (STL1). Peripheral chorioretinal atrophy with nyctalopia is prominent in WGN1. Intraretinal crystals may be visible in the periphery using a contact lens in SVD and corneal guttae, a flat appearance to the optic nerve head and mild atrophy of the peripheral retinal pigment epithelium are also common features. Other vitreoretinal degenerations including a number of chondrodysplasias in addition to STL1 and STL2, enhanced S-cone syndrome caused by mutations in NR2E3, and autosomal dominant vitreoretinochoroidopathy caused by mutations in VMD2 are discussed. Patients with unexplained early onset cataract or retinal detachment should be carefully evaluated for vitreoretinal degeneration. Theses diseases share overlapping clinical features with common complex traits affecting the eye (myopia, corneal endothelial dystrophy, lattice degeneration), and may provide insight into the mechanisms of common eye diseases.

Eye (2008) 22, 1233-1242; doi:10.1038/eye.2008.38; published online 29 February 2008

\section{Introduction}

Knowledge of the inherited vitreoretinopathies or vitreoretinal degeneration has expanded greatly over the past few years in conjunction with the identification of the disease genes for all of the classic syndromes. At the same time, numerous families with autosomal dominant and autosomal recessive vitreoretinal degeneration and a much greater number of singleton cases have yet to have the molecular bases of their diseases defined. Even so, recent genetic and clinical advances enable a reassessment of the essential criteria that define this group of conditions. For the purposes of this review, an inherited vitreoretinopathy is defined as a condition in which the major features are the presence of congenital abnormalities of the vitreous with severe degeneration or maldevelopment, early onset progressive cataract, and an increased predisposition to rhegmatogenous retinal detachment. Chondrodysplasias with vitreoretinal degeneration including Stickler syndrome, the chromosome $5 q$ retinopathies including Wagner syndrome, snowflake vitreoretinal degeneration (SVD), and autosomal dominant vitreoretinochoroidopathy (ADVIRC) are reviewed. Enhanced S-cone syndrome (ESCS) is discussed to distinguish it from the presentation of these vitreoretinopathies. Lattice degeneration, $X$-linked juvenile retinoschisis, and the hereditary neovascular vitreoretinopathies are not discussed. A detailed review of all of these conditions is available. ${ }^{1}$

Overview of examination and management

The detailed examination of a single patient with vitreoretinal degeneration will often
Department of Ophthalmology, Mayo

Clinic, Rochester, MN, USA

Correspondence: Dr AO Edwards, Department of Ophthalmology, Mayo Clinic, 200 First Street, SW Rochester, MN 55905, USA Tel: + 1507284 2787; Fax: + 15072844612 E-mail: edwardslab@ mayo.edu

Received: 18 January 2008 Accepted in revised form: 18 January 2008 Published online: 29 February 2008

Presented at the Cambridge Ophthalmological Symposium, Cambridge, UK, 6 September 2007. 
narrow the differential diagnosis, but may not be sufficient to identify the specific disorder or underlying genetic basis. Because many of the named syndromes are autosomal dominant, examination of other family members will often identify additional affected members and be sufficient to make an accurate diagnosis. Unfortunately, other family members are often not examined due to the physician's failure to recognize the hereditary nature of the disease or resistance from the family for financial or other reasons. As a result, the family does not receive the correct diagnosis, education, and follow-up important for the recognition and management of retinal detachment and cataract. The recent report of the efficacy of peripheral cryopexy for prevention of blindness and retinal detachment in the most common inherited vitreoretinopathy (Stickler syndrome type I, STL1) makes accurate diagnosis of relatives a key part of the management plan. ${ }^{2}$

The dismal prognosis prior to the development of closed cataract and vitrectomy techniques was due to the lack of vitreous support during surgery. Cataract surgery is difficult in these patients for this same reason, and should be performed by talented surgeons with experience with these patients or with vitrectomized eyes that behave similarly. Glaucoma can occur, usually after cataract surgery, and should be monitored and treated using established methods. Prophylactic cryopexy is performed by some groups, while peripheral laser retinopexy is favoured by others. Although a randomized trial has yet to be published comparing the two methods, the recent report using cryopexy is the most comprehensive study to date. ${ }^{2}$ The authors reported that the cryopexy was performed on the anterior retina, adjacent to the ora, to prevent the giant retinal tears that complicate STL1. Posterior retinal detachments are also common and managed with advanced vitreoretinal techniques including vitrectomy, completion of posterior vitreous detachment, release of peripheral traction, perflourocarbon-mediated retinal reattachment, scleral buckle, laser retinopexy, and tamponade with gas or silicone oil.

The remainder of this article reviews the common features of the vitreoretinal degenerations and highlights those features that can be used to distinguish them from each other clinically. An overview is presented in Table 1.

\section{Stickler syndrome and other chondrodysplasias associated with vitreoretinal degeneration}

\section{Key features}

The combination of (1) mid-face hypoplasia and small chin; (2) bifid uvula, submucous, or frank cleft palate; (3) congenital abnormalities of the vitreous; (4) cataract; and
(5) a high rate of retinal detachment characterize the Stickler syndromes with ocular involvement (Figure 1). STL1 arises due to mutations in COL2A1, while type 2 disease (STL2) arises from mutations in COL11A1. Most patients have STL1. Prophylactic therapy reduces the rate of retinal detachment making the identification of patients and their affected family members important. ${ }^{2}$

\section{Clinical features}

The systemic features of STL1, STL2, and the non-ocular form STL3 (COL11A2 mutations) are highly variable and do not distinguish between the three forms or even affected and unaffected family members in some cases. ${ }^{3}$ The ocular manifestations of STL1 and STL2 are highly penetrant and the eye examination is essential in making the diagnosis in some patients. Further, the eye examination enables patients with $C O L 2 A 1$ mutations to be distinguished from those with $C O L 11 A 1$ mutations. The COL2A1 patients have distinctive vitreous appearance in which a folded membrane is present behind the lens, behind which is advanced degeneration of the vitreous (membranous or type I vitreous). ${ }^{3}$ The COL11A2 patients have a fibrillar and beaded appearance to the vitreous (fibrillar or type II vitreous). ${ }^{4}$ Because the collagen genes are large and difficult to screen for mutations, the eye examination plays an important role not only in making the diagnosis, but also in directing genetic testing to COL2A1 (membranous vitreous) or COL11A1 (fibrillar vitreous). ${ }^{5}$

Other ocular features are characteristic of Stickler syndrome, but not diagnostic. The cataract is often described as comma or wedge-shaped and can present in childhood. Glaucoma has been observed, but does not appear to be common in the absence of prior ocular surgery. Radial perivascular chorioretinal degeneration is commonly seen in adults. ${ }^{6}$ This condition is different from radial lattice degeneration that is also observed. ${ }^{7}$ Circumferential lattice degeneration is often observed. The lattice degenerations have vitreous condensations overlying the atrophic retina, that is absent in radial perivascular chorioretinal degeneration. The optic nerve is normal. Rhegmatogenous retinal detachment occurs in over $50 \%$ of patients with Stickler syndrome. The retinal breaks are often anterior giant retinal tears or posterior breaks.

In addition to the genotype-phenotype correlation seen with the vitreous appearance, families with predominantly ocular Stickler syndrome are associated with mutations in exon 2 of COL $2 A 1 .^{8}$ In these families, systemic features are uncommon. ${ }^{9,10}$ Families with COL2A1 without detectable systemic features have been reported. ${ }^{11}$ 
Table 1 Common and differentiating features of vitreoretinal degenerations and related conditions ${ }^{\mathrm{a}}$

\begin{tabular}{|c|c|c|c|c|c|c|}
\hline Name & $\begin{array}{l}\text { Stickler syndrome } \\
\text { (types I and II) }\end{array}$ & Knobloch syndrome & $\begin{array}{l}\text { Enhanced S-cone } \\
\text { syndrome }\end{array}$ & $\begin{array}{l}\text { Autosomal dominant } \\
\text { vitreoretinochoroidopathy }\end{array}$ & Wagner disease & $\begin{array}{l}\text { Snowflake vitreoretinal } \\
\text { degeneration }\end{array}$ \\
\hline Abbreviation & STL1/STL2 & $\mathrm{KNO}$ & ESCS & ADVIRC & WGN1 & SVD \\
\hline Inheritance & Autosomal dominant & $\begin{array}{l}\text { Autosomal } \\
\text { recessive }\end{array}$ & $\begin{array}{l}\text { Autosomal } \\
\text { recessive }\end{array}$ & Autosomal dominant & Autosomal dominant & Autosomal dominant \\
\hline Chromosome & $12 q 13 / 1 p 21$ & $21 q 22$ & $15 q 22$ & $11 q 13$ & $5 q 13$ & $2 \mathrm{q} 36$ \\
\hline Genes & COL2A1/COL11A1 & COL18A1 & $N R 2 E 3$ & $V M D 2$ & CSPG2 & KCNJ13 \\
\hline Refraction/motility & Myopic & $\begin{array}{l}\text { Myopic, } \\
\text { nystagmus }\end{array}$ & Variable, myopic & Variable & $\begin{array}{l}\text { Myopia, pseudostrabismus } \\
\text { with positiv-angle } \kappa\end{array}$ & Myopia \\
\hline Anterior segment & Cataract & $\begin{array}{l}\text { Cataract, lens } \\
\text { subluxation }\end{array}$ & Usually normal & $\begin{array}{l}\text { Usually normal, but } \\
\text { dysgenesis and congenital } \\
\text { cataract reported }\end{array}$ & $\begin{array}{l}\text { Cataract, anterior segment } \\
\text { dysgenesis }\end{array}$ & Corneal guttae, cataract \\
\hline Vitreous & $\begin{array}{l}\text { Retrolental membrane/ } \\
\text { fibrillar and beaded }\end{array}$ & $\begin{array}{l}\text { Degeneration, } \\
\text { type unknown }\end{array}$ & $\begin{array}{l}\text { Usually normal, } \\
\text { may be degenerated } \\
\text { in Goldmann-Favre }\end{array}$ & $\begin{array}{l}\text { Normal to fibrillar } \\
\text { degeneration, cells }\end{array}$ & $\begin{array}{l}\text { Optically empty with } \\
\text { pre-retinal membranes }\end{array}$ & Fibrillar degeneration \\
\hline Optic nerve & Usually normal & Unknown & Usually normal & $\begin{array}{l}\text { May have } \\
\text { neovascularization }\end{array}$ & Optic atrophy & $\begin{array}{l}\text { Flat appearance, absent } \\
\text { cup, waxy pallor }\end{array}$ \\
\hline Macula & Usually normal & $\begin{array}{l}\text { Macular } \\
\text { degeneration and } \\
\text { staphyloma } \\
\text { reported }\end{array}$ & $\begin{array}{l}\text { Cystoid changes, } \\
\text { loss of normal } \\
\text { retinal lamellae }\end{array}$ & $\begin{array}{l}\text { May have macular edema } \\
\text { or atrophy }\end{array}$ & Initially preserved & Usually normal \\
\hline Retinal vessels & $\begin{array}{l}\text { Radial perivascular } \\
\text { retinal degeneration }\end{array}$ & $\begin{array}{l}\text { Persistence foetal } \\
\text { vasculature } \\
\text { reported }\end{array}$ & $\begin{array}{l}\text { Pigmentary } \\
\text { degeneration along } \\
\text { the arcades }\end{array}$ & $\begin{array}{l}\text { Pre-retinal } \\
\text { neovascularization } \\
\text { reported }\end{array}$ & $\begin{array}{l}\text { Perivascular pigmentation, } \\
\text { peripheral vascular } \\
\text { sheathing }\end{array}$ & $\begin{array}{l}\text { Parapapillary sheathing, } \\
\text { radial perivascular } \\
\text { degeneration }\end{array}$ \\
\hline Periphery & $\begin{array}{l}\text { Radial and } \\
\text { circumferential lattice, } \\
\text { anterior giant retinal } \\
\text { tears, posterior retinal } \\
\text { tears, retinal } \\
\text { detachment }(>50 \%)\end{array}$ & $\begin{array}{l}\text { Diffuse RPE } \\
\text { atrophy, retinal } \\
\text { detachment } \\
(>50 \%)\end{array}$ & $\begin{array}{l}\text { Peripheral } \\
\text { degeneration with } \\
\text { clumped pigment } \\
\text { may be present }\end{array}$ & $\begin{array}{l}\text { A sharply demarcated, } \\
\text { circumferential, peripheral } \\
\text { retinal degeneration from } \\
\text { ora serrata to a posterior } \\
\text { margin anterior to the } \\
\text { equator is typical, low rate } \\
\text { of retinal detachment }\end{array}$ & $\begin{array}{l}\text { Progressive chorioretinal } \\
\text { atrophy, tractional and } \\
\text { rhegmatogenous retinal } \\
\text { detachment (infrequent) }\end{array}$ & $\begin{array}{l}\text { Minute inner retinal } \\
\text { crystals, focal RPE } \\
\text { degeneration, vitreous } \\
\text { condensations, retinal } \\
\text { detachment }(20 \%)\end{array}$ \\
\hline Retinal function & Usually normal & $\begin{array}{l}\text { Probably reduced } \\
\text { ERG amplitudes } \\
\text { with delayed } \\
\text { implicit times }\end{array}$ & $\begin{array}{l}\text { Enhanced S-cone } \\
\text { ERG to } \\
\text { extinguished }\end{array}$ & $\begin{array}{l}\text { Depressed Arden ratio } \\
\text { with variable reduction in } \\
\text { ERG }\end{array}$ & $\begin{array}{l}\text { Nyctalopia, impaired dark } \\
\text { adaptation, and } \\
\text { progressive reduction in } \\
\text { ERG with greater } \\
\text { preservation of the b-wave }\end{array}$ & $\begin{array}{l}\text { Reduced dark adaptation, } \\
\text { scotopic b-wave reduction } \\
\text { in dim white light }\end{array}$ \\
\hline Systemic findings & $\begin{array}{l}\text { Mid-face hypoplasia, } \\
\text { micrognathia, hearing } \\
\text { loss, arthritis, other }\end{array}$ & $\begin{array}{l}\text { Occipital } \\
\text { enchepalocele or } \\
\text { scalp/hair defect }\end{array}$ & None & None & None & None \\
\hline
\end{tabular}

Abbreviations: ADVIRC, autosomal dominant vitreoretinochoroidopathy; ESCS, enhanced S-cone syndrome; ERG, electroretinogram; KNO, knoblock syndrome; RPE, retinal pigment epithelium; STL 1/2, Stickler syndrome types 1/2; WGN1, Wagner syndrome type I.

${ }^{a}$ Note that a given patient need not have all of the listed features. The pattern of clinical findings, rather than a specific feature is the best way to make the diagnosis. 
a
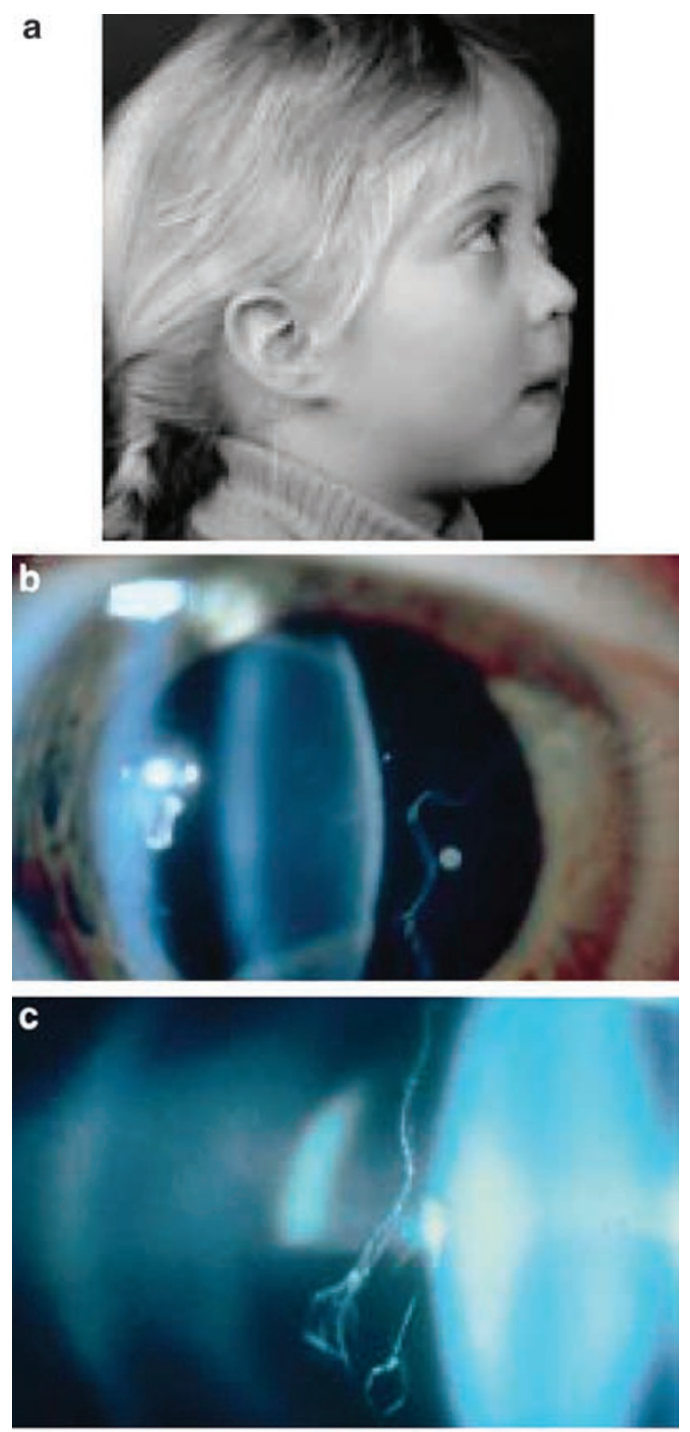

d

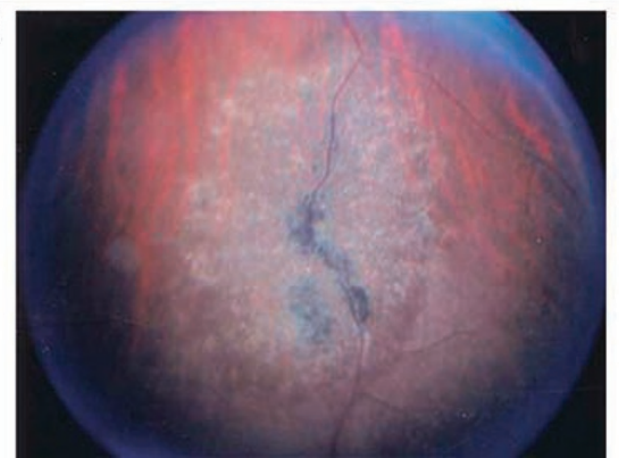

Figure 1 Clinical features of Stickler syndrome type I (STL1) and II (STL2). (a) Mid-face hypoplasia and micrognathia typical of STL in a child with a premature stop codon mutation in exon 13 of COL2A1 reported by Faber et al. ${ }^{47}(\mathrm{~b}, \mathrm{c})$ The membranous vitreous phenotype of STL1 (b) and the beaded phenotype of type II disease (c) reported by Richards et al. ${ }^{8}$ (d) Radial perivascular pigmentary chorioretinal degeneration in an STL1 patient reported by $\mathrm{Vu}$ et $a l^{7}$ All images are used with permission of the publisher.
Related chondrodysplasias with mutations in COL2A1 and COL11A1 may also present with vitreoretinal degeneration. These include Kniest dysplasia (autosomal dominant, short trunk dwarfism) and phalangeal epiphysial dysplasia with brachydactyly (autosomal dominant, normal stature) from COL2A1 mutations. ${ }^{12,13}$ Marshall syndrome arises due to mutations in COL11A1 and is distinguished by early and severe hearing loss with more pronounced facial abnormalities including severe mid-face hypoplasia, short nose, and anteverted nares. ${ }^{14}$ Splicing mutations of $54 \mathrm{bp}$ exons of COL11A1 appear to cause Marshall syndrome. ${ }^{15}$ Knobloch syndrome is an autosomal recessive condition characterized by vitreoretinal degeneration and congenital occipital encephalocele that arises from mutations in COL18A1. ${ }^{16}$

\section{Pathophysiology and management}

The ocular complications most commonly arise due to reduced dosage (haploinsufficiency) of COL2A1 through nonsense mutations. Cataract should be managed with phacoemulsification and closed fluidics due to the lack of vitreous support. Prophylactic cryotherapy was recently reported to markedly reduce the risk of retinal detachment in a retrospective study as mentioned above. ${ }^{2}$ Anterior retinal treatment that is contiguous or dense in nature should be offered to affected members of families around the age of 2 years. A correct diagnosis is essential when offering prophylactic therapy, increasing the importance of genetic testing and referral of new cases to clinicians with expertise with these conditions. Recently, autosomal recessive mutations in COL9A1 were reported to cause a Stickler-like condition. ${ }^{17}$

Although the description of the ophthalmic findings did not appear to be classic for Stickler syndrome, this report does raise the possibility that the risk for an additional affected child could be much higher in rare cases than would be expected for a new autosomal dominant disease.

\section{Enhanced S-cone syndrome and Goldmann-Favre vitreotapetoretinal degeneration}

\section{Key features}

Mutations in a retinal nuclear receptor (NR2E3) involved in suppressing cone proliferation during retinal development lead to a group of diseases usually referred to as ESCS. ${ }^{18}$ The classic presentation is nyctalopia with cystoid macular abnormalities, pigmentary degeneration along the arcades, or clumped peripheral retinal pigmentation (Figure 2). The electroretinogram (ERG) shows absent rod-isolated responses under dark 

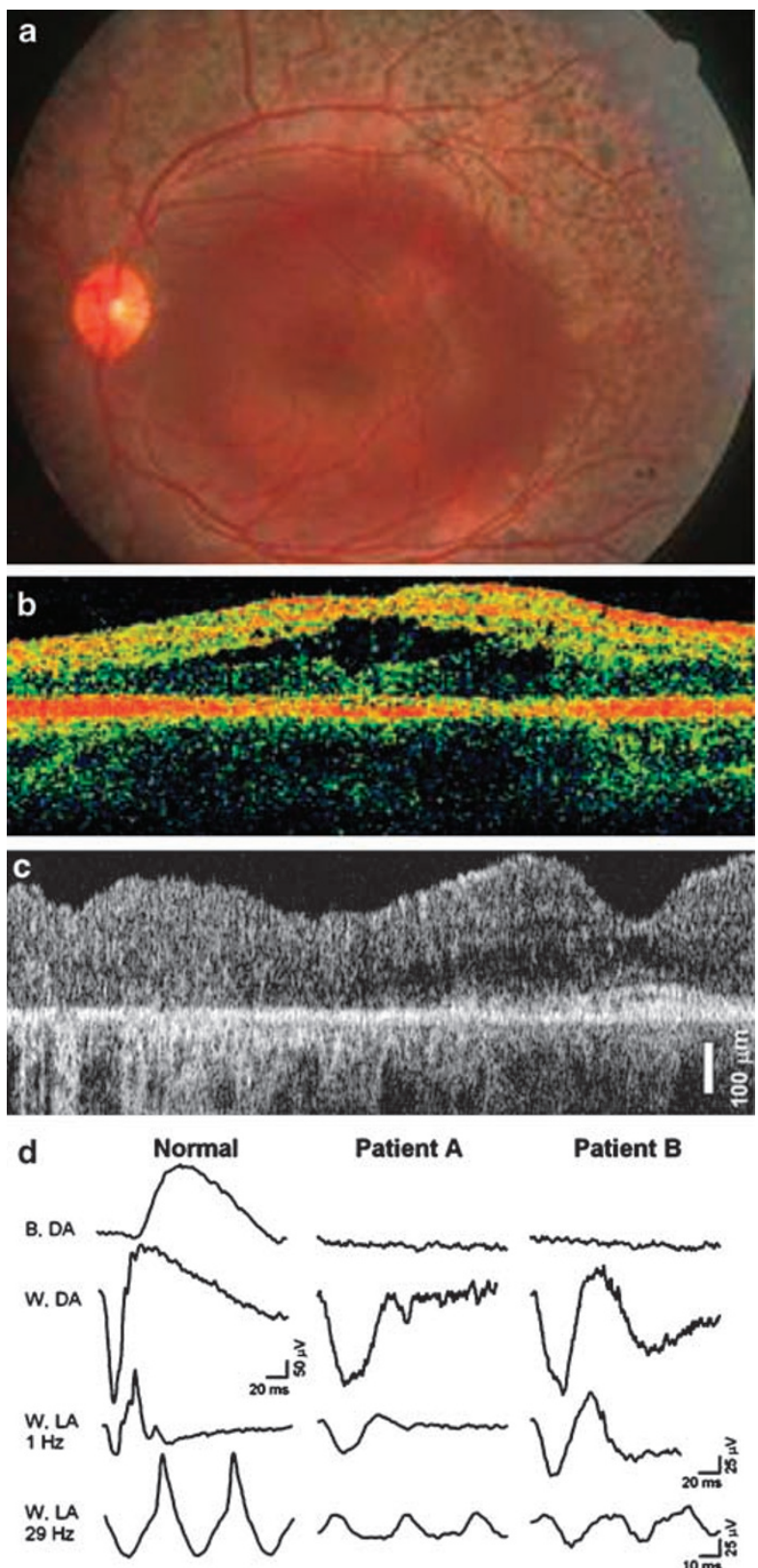

Patient B

Figure 2 Clinical features of enhanced S-cone syndrome (ESCS). (a) Typical fundus appearance of a patient with a mutation in NR2E3 causing ESCS. Note the grouped pigment and relative sparing of the macula reported by Nakamura et al. ${ }^{48}(\mathrm{~b}, \mathrm{c})$ Macular cysts typical of ESCS as reported by Wright et $a l^{2}$ using optical coherence tomography (b) and loss of normal retinal laminae as reported by Jacobson et al (c). ${ }^{24}$ (d) Enhanced S-cone electroretinogram (ERG) as reported by Wright et al. ${ }^{22}$ The rod-isolated response (B, DA) is reduced or absent while the combined rod-cone response in dark adaptation (W, DA) and the cone response in light adaptation (W, LA) show similar broadened, delayed, and largely negative responses. All images are used with permission of the publisher.

adaptation, while rod and cone dark-and light-adapted waveforms are similar with delayed and broadened responses. ${ }^{19}$ Very rare cases present with vitreoretinal degeneration, and these are referred to as GoldmannFavre. Thus, ESCS may best be categorized as a retinal degeneration with macular and retinal degeneration, rather than a vitreoretinal degeneration.

\section{Clinical features}

The classic presentation of ESCS is cystoid macular changes with pigmentary retinal degeneration along the arcades or in the periphery. Vitreous degeneration, peripheral retinoschisis, and cataract are absent. More advanced cases can show a diffuse retinal degeneration with the formation of pigmentary clumps and present with autosomal dominant retinitis pigmentosa. ${ }^{20}$ The most severe manifestation of mutations in NR2E3 is a vitreoretinal degenerations with fibrillar degeneration of the vitreous, early onset cataract, and diffuse retinal degeneration with retinoschisis and peripheral clumped retinal pigmentation. ${ }^{21}$ The ERG findings described in the previous paragraph are shared between the various presentations of NR2E3 mutations. In addition, S-cone isolated responses are greater than normal, except in advanced cases when the ERG may be extinguished. This ESCS phenotype is associated with NR2E3 mutations in $95 \%$ or more of cases. ${ }^{22}$

\section{Pathophysiology and management}

In the presence of the cone rod homeobox protein (CRX), NR2E3 binds to opsin promoters to promote transcription of rhodopsin while repressing cone opsin expression. In the absence of NR2E3, it is thought that $C R X$ and NRL leave immature rods with the option of developing into $\mathrm{S}$ cones or degenerating. ${ }^{23}$ Degeneration of the retina may lead to loss of retinal lamination on optical coherence tomography. ${ }^{24}$ The classic ESCS fundus may arise because the regions along and just outside the arcades normally have the greatest density of rods and thus are most susceptible to degeneration from cone-like ESCS photoreceptors. ${ }^{24}$

\section{Autosomal dominant vitreoretinochoroidopathy}

\section{Key features}

Autosomal dominant vitreoretinochoroidopathy was first reported in 1982 by Kaufman et al..$^{25}$ The condition arises due to mutations in the gene for Best disease (VMD2). ${ }^{26}$ The characteristic feature is a peripheral annular pigmentary dystrophy of the retina (Figure 3). The light rise of the electrooculogram is decreased giving a reduced Arden ratio. ${ }^{27}$ 

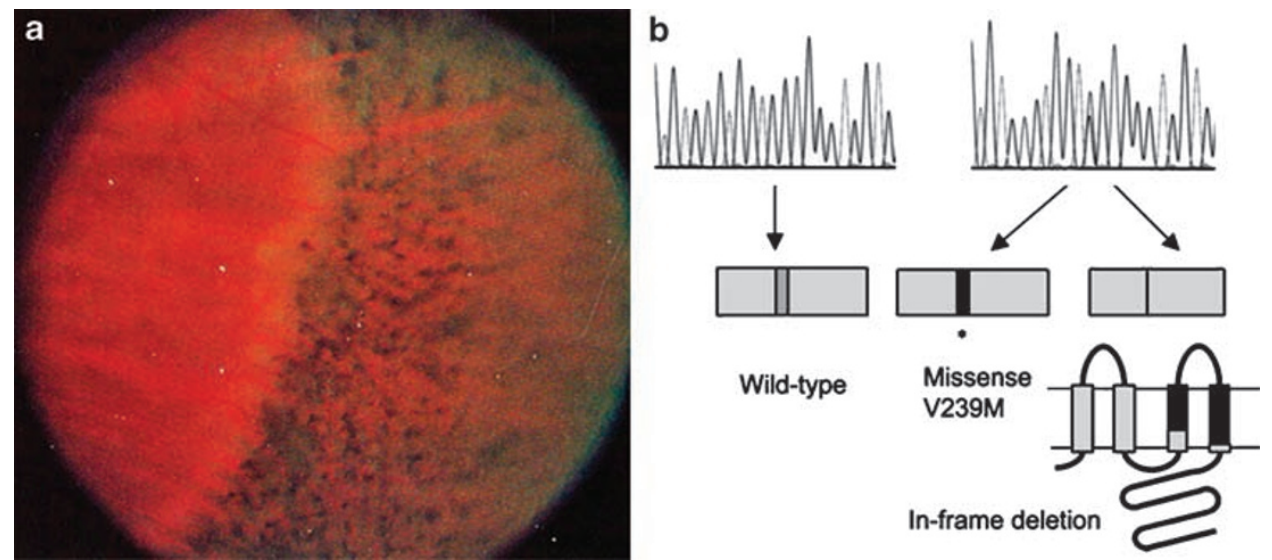

Figure 3 Autosomal dominant vitreoretinochoroidopathy (ADVIRC). (a) Classic fundus appearance for ADVIRC as first reported by Kaufman et al in 1982. Note the peripheral pigmentary band of retinal degeneration and the hypopigmented zone between relatively normal and degenerated retina. ${ }^{25}$ (b) Yardley et $a l^{26}$ proposed that missense mutations without altered splicing lead to Best disease, while those with altered splicing that gives rise to protein products with in-frame deletions lead to ADVIRC. Note that heterozygous patients with autosomal dominant ADVIRC are predicted to produce the wild-type protein, the missense protein, and one or more proteins with in-frame deletions. All images are used with permission of the publisher.

\section{Clinical features}

The peripheral annular pigmentary dystrophy of the retina is a band of chorioretinal atrophy extending from the ora serrata to a variable degree posteriorly. The posterior margin is typically anterior to the equator and shows a distinct border between the anterior degenerated retina and typically normal posterior retina. A hypopigmented border may be present. Fibrillar vitreous degeneration with vitreous cells may be present.

Neovascularization of the optic disc or posterior retinal surface has been described in several patients and vitreous haemorrhage may occur. Macular oedema may be present. Some families exhibit congenital anterior segment abnormalities including nanophthalmus, microcornea, angle closure glaucoma, and congenital cataract. ${ }^{26}$ Lattice degeneration and radial perivascular retinal degeneration have not been observed, although cataract and rarely retinal detachment may be present. Although central visual function is usually good, some patients may experience vision loss associated with central depression of the multifocal ERG. ${ }^{28}$ Full-field ERGs may be normal or reduced to a variable degree. The histopathology for two patients has been reported showing intraretinal migration of the retinal pigment epithelium and deposition of extracellular matrix. ${ }^{29}$

\section{Pathophysiology and management}

Yardley $e a^{26}$ showed that single base pair sequence variants that create both missense mutations and alternatively spliced messages give rise to ADVIRC. These mutations lead to mutated VMD2 protein products with both amino-acid mutations and one or more inframe deletions. Alternatively, spliced products were not observed with mutations in VMD2 that give rise to Best disease. The frequent occurrence of choroidal neovascularization in Best disease relative to other macular dystrophies and the occurrence of retinal neovascularization in ADVIRC suggest that Best disease patients with neovascularization might have alternative splicing. The author has successfully used intravitreally delivered anti-vascular endothelial growth factor antibodies in the management of the neovascular complications of ADVIRC. Patients have been reported in which retinal photocoagulation was applied to treat retinal neovascularization, but the success of therapy is unclear. $^{30}$

The chromosome $5 q$ retinopathies: Wagner syndrome, Jansen syndrome, erosive vitreoretinopathy, and related families

\section{Key features}

Wagner first reported this condition in a Swiss family in 1938. ${ }^{31}$ Mutations in a chondroitin sulphate proteoglycan (CSPG2) that binds to hyaluronan in the vitreous were first reported by Miyamoto in 2005. ${ }^{32}$ Wagner syndrome is distinguished by a congenitally optically empty vitreous with pre-retinal vitreous condensations. ${ }^{33}$ Pseudoexotropia and progressive chorioretinal degeneration are typical findings (Figure 4). ${ }^{32,34}$ 

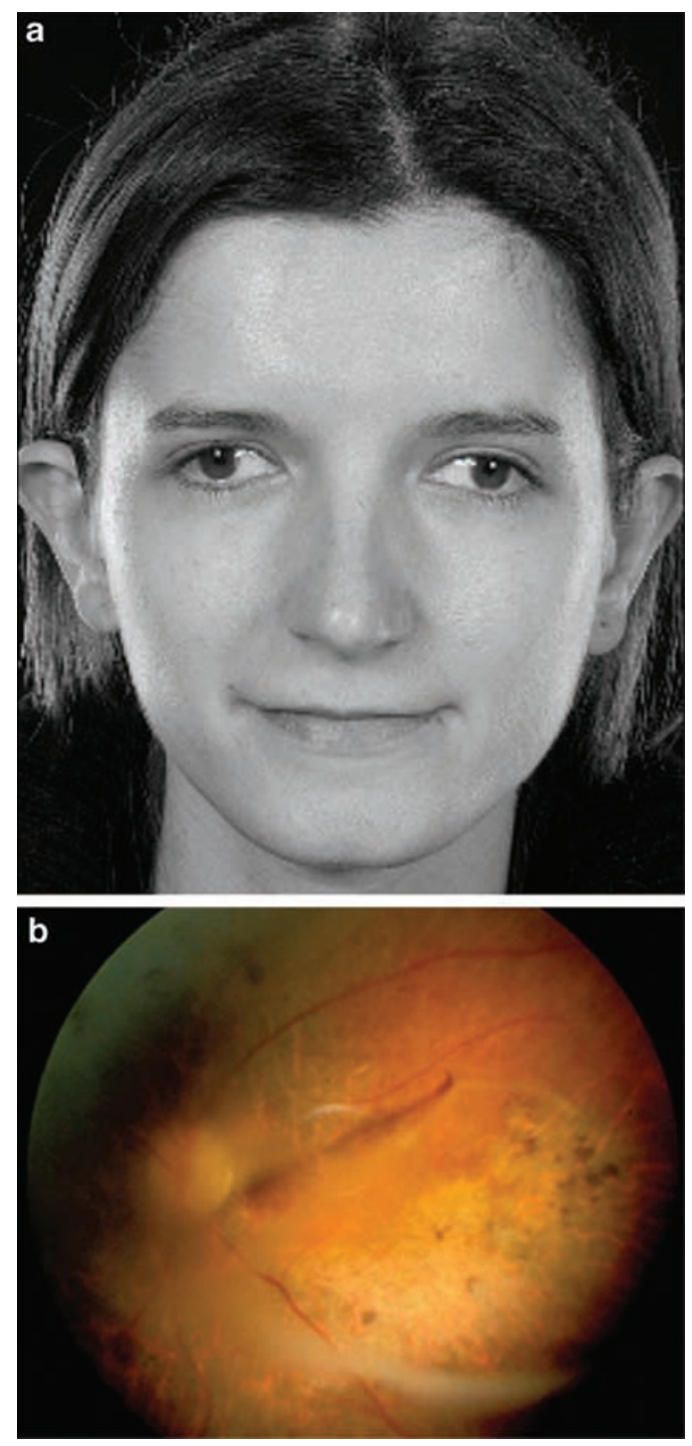

Figure 4 Wagner syndrome (WGN1). (a) Pseudostrabismus in a patient reported by Meredith et al, a finding typical of Wagner syndrome noted by Maumenee in 1982 in the original Wagner family and recently by Miyamoto et $a .^{32,34,37}$ (b) Pre-retinal membranes and chorioretinal atrophy in a patient with Wagner syndrome due to a splicing mutation in versican (CSPG2) reported by Meredith et al. ${ }^{37}$ All images are used with permission of the publisher.

\section{Clinical features}

Patients with Wagner syndrome present early in life with pseudostrabismus from congenital temporal

displacement of the fovea and an optically empty central vitreous cavity with pre-retinal membranes extending from the posterior pole towards the periphery. ${ }^{34}$ Some authors have described fibrillary vitreous condensations. Congenital abnormalities such as microphthalmia, ectopia lentis, iris atrophy, persistent hyperplastic primary vitreous, and tractional retinal detachment were reported in some families. ${ }^{35}$ Initially the vision is usually normal, but progressive chorioretinal atrophy often starting in the periphery leads to severe loss of vision. ${ }^{33}$ The rate of retinal detachment varies from a few percent to $75 \%$ in some pedigrees. ${ }^{33,36}$ Nyctalopia can be present early in life and final dark adaptation thresholds were elevated in some reported patients. The ERG may be normal early in life or shows reduction in the scotopic b-wave; diffuse cone-rod loss ensues as chorioretinal atrophy develops. ${ }^{33}$ The visual field can show a ring scotoma or advanced loss as the chorioretinal atrophy progresses and the ERG can become extinguished.

\section{Pathophysiology and management}

Sequence variants in versican (CSPG2) have been reported for the original Wagner family, a Japanese family, three Dutch families, and a British family. ${ }^{32,37-39}$ These sequence variants occurred at or near the 3 -acceptor splice site of intron 7 . The mutations result in a 40 -fold or greater increase in the relative abundance of the CSPG2 splice variants without exon 8, a 10-fold or greater increase in forms without exon 7 or exon 8 , and a modest reduction in variants with exon 8 . Even when a mutation cannot be identified, the abnormal splicing can be detected in patients with Wagner syndrome, demonstrating that an undetected intronic variant is probably causing the disease. ${ }^{38}$ These two exons ( 7 and 8 ) contain the glycosaminoglycan attachment sites that support chondroitin sulphate side chain aggregation. The glycoprotein binds hyaluronate and link protein to form large aggregates that support vitreous integrity. At present, it is unknown if the altered protein isoforms that may arise due to abnormal splicing can account for the variability in phenotype expression or the congenital and acquired features of the disease. Cataract and retinal detachment in Wagner syndrome patients are managed using standard approaches as discussed above.

\section{Snowflake vitreoretinal degeneration}

\section{Key features}

This condition was originally described by Hirose et al in $1974 .^{40}$ Lee $e t a l^{41}$ and Jiao et $a l^{42}$ re-examined the family and localized the mutation to chromosome $2 \mathrm{q} 36$, confirming that SVD is a distinct disease. The condition arises due to a mutation in KCNJ13 disrupting the selective transport of potassium through the channel. ${ }^{43}$ Although the term Snowflake has been used in some reports of other families, at this time they do not appear to be the same condition by clinical criteria or genetic evaluation. ${ }^{1}$ The key distinguishing features are fibrillar 


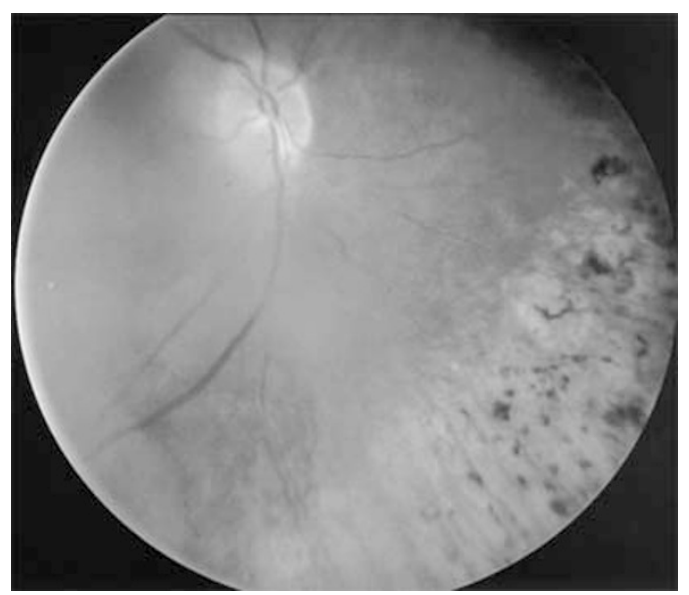

Figure 5 Snowflake vitreoretinal degeneration (SVD). A fundus photograph of a patient in the original Snowflake family first published by Hirose $e t$ al and re-assessed by Lee et al. ${ }^{40,41}$ Note the flat dysmorphic optic nerve head, sheathing of vessels on the optic nerve head, fibrillar degeneration of the vitreous, and peripheral chorioretinal atrophy. All images are used with permission of the publisher.

degeneration of the vitreous, optic nerve dysmorphism, peripheral areas of retinal pigment epithelial degeneration, corneal guttae, and retinal crystals (Figure 5).

\section{Clinical features}

Snowflake vitreoretinal degeneration has the classical features of the vitreoretinal degeneration including optically empty vitreous, early onset cataract, and perivascular retinal degeneration. There is a low rate of retinal detachment, occurring in $20 \%$ of family members. ${ }^{41}$ The vitreous degeneration is fibrillar to a variable extent; the bands of condensed vitreous fibrils may obscure fundus details and peripheral condensations of vitreous on the retinal surface can be observed. Lattice degeneration (radial or circumferential) was not observed. The average spherical equivalent was -2.90 dioptres indicating moderate myopia. Corneal abnormalities have not been reported in the VRDs, except for SVD in which corneal guttae identical in appearance to Fuchs endothelial corneal dystrophy were observed in the original family. ${ }^{41}$ The condition received its name from the minute inner retinal crystals that can be seen using a contact lens in some patients. ${ }^{40}$ Other distinguishing features include a dysmorphic optic nerve head that appears flat and often without a cup. Parapapillary vascular sheathing and atrophy, as well as waxy pallor may be present. Peripheral retinal pigment epithelium degeneration in equatorial location may be present. The vision is usually good, even though psychophysical testing shows elevated dark adaptation and reduction of the scotopic b-wave in dim white light. $^{44}$

\section{Pathophysiology and management}

The mutation in KCNJ13 demonstrates that classical vitreoretinal degeneration can arise from mutation in genes that are not structural components of the vitreous. The alteration in potassium transport provides a mechanism for the electrophysiological abnormalities seen in these patients, but further study is required for a precise explanation. The localization of Kir7.1 (the protein product of KCNJ13) to the retinal pigment epithelium and internal limiting membranes suggests that the mutation could alter development of the vitreous through altering Muller cell function. At this time, no specific management is available.

\section{Autosomal recessively inherited vitreoretinal dystrophy}

Sarra et a $l^{45}$ reported an autosomal recessive inherited vitreoretinopathy showing ocular phenotypic overlap with Knobloch and Wagner syndromes. Macular atrophy, fibrillar vitreous degeneration, ectopia lentis and cataract, diffuse peripheral retinal degeneration, and high myopia with retinal tears and detachment. However, no systemic features were observed and linkage analysis was not consistent with known disease loci. The condition was linked to chromosome $22 q 13 .{ }^{46}$

\section{Acknowledgements}

This work was supported in part by grants from the National Eye Institute (EY014467), the Foundation Fighting Blindness, Research to Prevent Blindness, and the Mayo Clinic. I am grateful to the patients and their family members for participating in the research.

\section{Conflict of interest}

The author has no conflicts of interest related to this paper.

\section{References}

1 Edwards AO, Robertson JE. Hereditary vitreoretinal degenerations. In: Ryan SJ, Hinton DR, Schachat AP, Wilkenson P (ed). Retina, 4th edn. Elsevier: Philadelphia 2006, pp 519-538.

2 Ang A, Poulson AV, Goodburn SF, Richards AJ, Scott JD, Snead MP. Retinal detachment and prophylaxis in type 1 Stickler syndrome. Ophthalmology 2008; 115: 164-168. 
3 Snead MP, Yates JR. Clinical and molecular genetics of Stickler syndrome. J Med Genet 1999; 36: 353-359.

4 Poulson AV, Hooymans JM, Richards AJ, Bearcroft P, Murthy R, Baguley DM et al. Clinical features of type 2 Stickler syndrome. J Med Genet 2004; 41: e107.

5 Richards AJ, Laidlaw M, Whittaker J, Treacy B, Rai H, Bearcroft $\mathrm{P}$ et al. High efficiency of mutation detection in type 1 Stickler syndrome using a two-stage approach: vitreoretinal assessment coupled with exon sequencing for screening COL2A1. Hum Mutat 2006; 27: 696-704.

6 Hagler WS, Crosswell Jr HH. Radial perivascular chorioretinal degeneration and retinal detachment. Trans Am Acad Ophthalmol Otolaryngol 1968; 72: 203-216.

$7 \mathrm{Vu}$ CD, Brown Jr J, Korkko J, Ritter III R, Edwards AO. Posterior chorioretinal atrophy and vitreous phenotype in a family with Stickler syndrome from a mutation in the COL2A1 gene. Ophthalmology 2003; 110: 70-77.

8 Richards AJ, Martin S, Yates JR, Scott JD, Baguley DM, Pope FM et al. COL2A1 exon 2 mutations: relevance to the Stickler and Wagner syndromes. Br J Ophthalmol 2000; 84: 364-371.

9 Donoso LA, Edwards AO, Frost AT, Ritter R, Ahmad NN, Vrabec $\mathrm{T}$ et al. Identification of a stop codon mutation in exon 2 of the collagen 2A1 gene in a large Stickler syndrome family. Am J Ophthalmol 2002; 134: 720-727.

10 Donoso LA, Edwards AO, Frost AT, Ritter III R, Ahmad N, Vrabec $\mathrm{T}$ et al. Clinical variability of Stickler syndrome: role of exon 2 of the collagen COL2A1 gene. Surv Ophthalmol 2003; 48: 191-203.

11 Richards AJ, Meredith S, Poulson A, Bearcroft P, Crossland $\mathrm{G}$, Baguley DM et al. A novel mutation of COL2A1 resulting in dominantly inherited rhegmatogenous retinal detachment. Invest Ophthalmol Vis Sci 2005; 46: 663-668.

12 Yokoyama T, Nakatani S, Murakami A. A case of Kniest dysplasia with retinal detachment and the mutation analysis. Am J Ophthalmol 2003; 136: 1186-1188.

13 Richards AJ, Morgan J, Bearcroft PW, Pickering E, Owen MJ, Holmans $\mathrm{P}$ et al. Vitreoretinopathy with phalangeal epiphyseal dysplasia, a type II collagenopathy resulting from a novel mutation in the C-propeptide region of the molecule. J Med Genet 2002; 39: 661-665.

14 Majava M, Hoornaert KP, Bartholdi D, Bouma MC, Bouman $\mathrm{K}$, Carrera $\mathrm{M}$ et al. A report on 10 new patients with heterozygous mutations in the COL11A1 gene and a review of genotype-phenotype correlations in type XI collagenopathies. Am J Med Genet A 2007; 143: 258-264.

15 Annunen S, Korkko J, Czarny M, Warman ML, Brunner HG, Kääriäinen $\mathrm{H}$ et al. Splicing mutations of 54-bp exons in the COL11A1 gene cause Marshall syndrome, but other mutations cause overlapping Marshall/Stickler phenotypes. Am J Hum Genet 1999; 65: 974-983.

16 Menzel O, Bekkeheien RC, Reymond A, Fukai N, Boye E, Kosztolanyi $\mathrm{G}$ et al. Knobloch syndrome: novel mutations in COL18A1, evidence for genetic heterogeneity, and a functionally impaired polymorphism in endostatin. Hum Mutat 2004; 23: 77-84.

17 Van Camp G, Snoeckx RL, Hilgert N, van den Ende J, Fukuoka H, Wagatsuma $\mathrm{M}$ et al. A new autosomal recessive form of Stickler syndrome is caused by a mutation in the COL9A1 gene. Am J Hum Genet 2006; 79: 449-457.

18 Haider NB, Jacobson SG, Cideciyan AV, Swiderski R, Streb $\mathrm{LM}$, Searby $\mathrm{C}$ et al. Mutation of a nuclear receptor gene, $N R 2 E 3$, causes enhanced $\mathrm{S}$ cone syndrome, a disorder of retinal cell fate. Nat Genet 2000; 24: 127-131.
19 Marmor MF, Jacobson SG, Foerster MH, Kellner U, Weleber RG. Diagnostic clinical findings of a new syndrome with night blindness, maculopathy, and enhanced $\mathrm{S}$ cone sensitivity. Am J Ophthalmol 1990; 110: 124-134.

20 Sharon D, Sandberg MA, Caruso RC, Berson EL, Dryja TP. Shared mutations in NR2E3 in enhanced S-cone syndrome, Goldmann-Favre syndrome, and many cases of clumped pigmentary retinal degeneration. Arch Ophthalmol 2003; 121: 1316-1323.

21 Chavala SH, Sari A, Lewis H, Pauer GJ, Simpson E, Hagstrom SA et al. An Arg311Gln NR2E3 mutation in a family with classic Goldmann-Favre syndrome. $\mathrm{Br} J$ Ophthalmol 2005; 89: 1065-1066.

22 Wright AF, Reddick AC, Schwartz SB, Ferguson JS, Aleman TS, Kellner U et al. Mutation analysis of NR2E3 and NRL genes in enhanced S cone syndrome. Hum Mutat 2004; 24: 439.

23 Peng GH, Ahmad O, Ahmad F, Liu J, Chen S. The photoreceptor-specific nuclear receptor Nr2e3 interacts with Crx and exerts opposing effects on the transcription of rod versus cone genes. Hum Mol Genet 2005; 14: 747-764.

24 Jacobson SG, Sumaroka A, Aleman TS, Cideciyan AV, Schwartz SB, Roman AJ et al. Nuclear receptor NR2E3 gene mutations distort human retinal laminar architecture and cause an unusual degeneration. Hum Mol Genet 2004; 13: 1893-1902.

25 Kaufman SJ, Goldberg MF, Orth DH, Fishman GA, Tessler H, Mizuno K. Autosomal dominant vitreoretinochoroidopathy. Arch Ophthalmol 1982; 100: 272-278.

26 Yardley J, Leroy BP, Hart-Holden N, Lafaut BA, Loeys B, Messiaen LM et al. Mutations of VMD2 splicing regulators cause nanophthalmos and autosomal dominant vitreoretinochoroidopathy (ADVIRC). Invest Ophthalmol Vis Sci 2004; 45: 3683-3689.

27 Han DP, Lewandowski MF. Electro-oculography in autosomal dominant vitreoretinochoroidopathy. Arch Ophthalmol 1992; 110: 1563-1567.

28 Oh KT, Vallar C. Central cone dysfunction in autosomal dominant vitreoretino choroidopathy (ADVIRC). Am J Ophthalmol 2006; 141: 940-943.

29 Goldberg MF, Lee FL, Tso MO, Fishman GA. Histopathologic study of autosomal dominant vitreoretinochoroidopathy. Peripheral annular pigmentary dystrophy of the retina. Ophthalmology 1989; 96: 1736-1746.

30 Blair NP, Goldberg MF, Fishman GA, Salzano T. Autosomal dominant vitreoretinochoroidopathy (ADVIRC). $\mathrm{Br}$ J Ophthalmol 1984; 68: 2-9.

31 Wagner H. Ein bisher unbekanntes erbleiden des auges (degeneratio hyaloideo-retinalis hereditaria), beobachtet im Kanton Zurich. Klinische monatsblatter fur augenheilkunde 1938; 100: 840-857.

32 Miyamoto T, Inoue H, Sakamoto Y, Kudo E, Naito T, Mikawa $\mathrm{T}$ et al. Identification of a novel splice site mutation of the CSPG2 gene in a Japanese family with Wagner syndrome. Invest Ophthalmol Vis Sci 2005; 46: 2726-2735.

33 Graemiger RA, Niemeyer G, Schneeberger SA, Messmer EP. Wagner vitreoretinal degeneration. Follow-up of the original pedigree. Ophthalmology 1995; 102: 1830-1839.

34 Maumenee IH, Stoll HU, Mets MB. The Wagner syndrome versus hereditary arthroophthalmopathy. Trans $A m$ Ophthalmol Soc 1982; 80: 349-365.

35 Black GC, Perveen R, Wiszniewski W, Dodd CL, Donnai D, McLeod D. A novel hereditary developmental vitreoretinopathy with multiple ocular abnormalities 
localizing to a 5-cM region of chromosome 5q13-q14. Ophthalmology 1999; 106: 2074-2081.

36 Brown DM, Kimura AE, Weingeist TA, Stone EM. Erosive vitreoretinopathy. A new clinical entity. Ophthalmology 1994; 101: 694-704.

37 Meredith SP, Richards AJ, Flanagan DW, Scott JD, Poulson AV Snead MP. Clinical characterisation and molecular analysis of Wagner syndrome. Br J Ophthalmol 2007; 91: 655-659.

38 Mukhopadhyay A, Nikopoulos K, Maugeri A, de Brouwer $\mathrm{AP}$, van Nouhuys $\mathrm{CE}$, Boon $\mathrm{CJ}$ et al. Erosive vitreoretinopathy and Wagner disease are caused by intronic mutations in CSPG2/Versican that result in an imbalance of splice variants. Invest Ophthalmol Vis Sci 2006; 47: 3565-3572.

39 Kloeckener-Gruissem B, Bartholdi D, Abdou MT, Zimmermann DR, Berger W. Identification of the genetic defect in the original Wagner syndrome family. Mol Vis 2006; 12: 350-355.

40 Hirose T, Lee KY, Schepens CL. Snowflake degeneration in hereditary vitreoretinal degeneration. Am J Ophthalmol 1974; 77: 143-153.

41 Lee MM, Ritter III R, Hirose T, Vu CD, Edwards AO. Snowflake vitreoretinal degeneration: follow-up of the original family. Ophthalmology 2003; 110: 2418-2426.

42 Jiao X, Ritter III R, Hejtmancik JF, Edwards AO. Genetic linkage of snowflake vitreoretinal degeneration to chromosome 2q36. Invest Ophthalmol Vis Sci 2004; 45: 4498-4503.
43 Hejtmancik JF, Jiao X, Li A, Sergeev YV, Ding X, Sharma AK et al. Mutations in KCNJ13 cause autosomal dominant snowflake vitreoretinal degeneration. Am J Hum Genet 2008; 82(1): 174-180.

44 Hirose T, Wolf E, Schepens CL. Retinal functions in snowflake degeneration. Ann Ophthalmol 1980; 12 1135-1146.

45 Sarra GM, Weigell-Weber M, Kotzot D, Niemeyer G, Messmer E, Hergersberg M. Clinical description and exclusion of candidate genes in a novel autosomal recessively inherited vitreoretinal dystrophy. Arch Ophthalmol 2003; 121: 1109-1116.

46 Weigell-Weber M, Sarra GM, Kotzot D, Sandkuijl L Messmer E, Hergersberg M. Genomewide homozygosity mapping and molecular analysis of a candidate gene located on 22q13 (fibulin-1) in a previously undescribed vitreoretinal dystrophy. Arch Ophthalmol 2003; 121: 1184-1188.

47 Faber J, Winterpacht A, Zabel B, Gnoinski W, Schinzel A, Steinmann B et al. Clinical variability of Stickler syndrome with a COL2A1 haploinsufficiency mutation: implications for genetic counselling. J Med Genet 2000; 37: 318-320.

48 Nakamura Y, Hayashi T, Kozaki K, Kubo A, Omoto S, Watanabe A et al. Enhanced S-cone syndrome in a Japanese family with a nonsense NR2E3 mutation (Q350X). Acta Ophthalmol Scand 2004; 82: 616-622. 